\title{
Development of thermo-photo sensitive genic male sterile lines in wheat using doubled haploid breeding
}

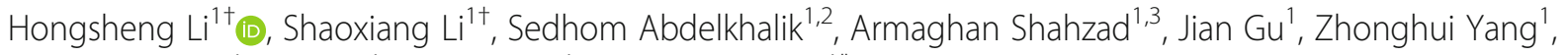
Mingliang Ding ${ }^{1}$, Kun Liu ${ }^{1}$, Hong Zhao ${ }^{1}$ and Mujun Yang ${ }^{1 *}$ (D)

\begin{abstract}
Background: Two-line hybrid wheat system using thermo-photo sensitive genic male sterility (TPSGMS) is currently the most promising approach for wheat heterosis utilization in China. However, during past 20 years only few TPSGMS lines were developed in hybrid wheat breeding, which has been the main limiting factor to create heterotic hybrids. Application of doubled haploid $(\mathrm{DH})$ breeding provides a useful strategy to efficiently develop practically usable TPSGMS lines.

Results: $F_{1} s$ and selected $F_{2}$ and $F_{3}$ sterile plants of eight crosses made from two commercial TPSGMS lines were used to produce DH lines. We developed a total of 24 elite DH sterile lines with stable sterility, good outcrossing and yield potential, resistance to yellow rust and powdery mildew, as well as desirable plant height $(50-60 \mathrm{~cm})$. These $\mathrm{DH}$ lines were developed within 4 years through at least 1 year of evaluation. The stability of male sterility was confirmed for most (20/24) of these elite DH sterile lines by multiple tests in two or 3 years. These lines are expected to be used in hybrid wheat breeding. The percentage of elite lines developed from the tested $\mathrm{DH}$ lines produced from filial generations was in the order of $F_{2}>F_{3}>F_{1}$.

Conclusions: We demonstrate that coupling $\mathrm{DH}$ techniques with conventional breeding is an efficient strategy for accelerating the development of more practical wheat TPSGMS lines. Generation of DHs from $\mathrm{F}_{2}$ generation appeared to be the better choice considering the balance of shortening breeding time and overall breeding efficiency.
\end{abstract}

Keywords: Hybrid wheat, Two lines system, Thermo-photo sensitive genic male sterility, Doubled haploid, Wheat × maize

\section{Background}

Wheat provides about $20 \%$ of the world's nutrition supply [1]. Heterosis utilization in wheat is one of the most promising ways for increasing yield potential and stability, which has importance for increasing the productivity of wheat to meet the growing demand in the world [2-4]. However, developing hybrids with high level of heterosis and producing

\footnotetext{
* Correspondence: kmyangmj@163.com

${ }^{+}$Hongsheng Li and Shaoxiang Li contributed equally to this work.

IInstitute of Food Crops, Yunnan Academy of Agricultural Sciences / Yunnan Branch of National Wheat Improvement Center, Kunming, Yunnan 650205, P. R. China

Full list of author information is available at the end of the article
}

hybrid seeds with low cost remain challenges in hybrid wheat breeding and its commercial application $[1,4]$.

Unlike hybrid wheat systems based on cytoplasmic male sterility (CMS) [5] and photoperiod-sensitive cytoplasmic male sterility (PCMS) [6], the two-line hybrid wheat system using thermo-photo sensitive genic male sterility (TPSGMS) is a new methodology of wheat heterosis utilization in China. The TPSGMS line is characterized as being sterile under low-temperature and short-day for hybrid seed production, and fertile under high-temperature and long-day for self propagation. Therefore, this system does not need a sterility 'maintainer' line and makes hybrid seed production easier

(c) The Author(s). 2020 Open Access This article is licensed under a Creative Commons Attribution 4.0 International License, which permits use, sharing, adaptation, distribution and reproduction in any medium or format, as long as you give appropriate credit to the original author(s) and the source, provide a link to the Creative Commons licence, and indicate if changes were made. The images or other third party material in this article are included in the article's Creative Commons licence, unless indicated otherwise in a credit line to the material. If material is not included in the article's Creative Commons licence and your intended use is not permitted by statutory regulation or exceeds the permitted use, you will need to obtain permission directly from the copyright holder. To view a copy of this licence, visit http://creativecommons.org/licenses/by/4.0/. The Creative Commons Public Domain Dedication waiver (http://creativecommons.org/publicdomain/zero/1.0/) applies to the data made available in this article, unless otherwise stated in a credit line to the data. 
[7-9]. From 2002 to 2018, 20 hybrid wheat varieties were released in China [10], 14 of them were developed using TPSGMS-based two-line system with yield increase of 10 $15 \%$, especially in marginal lands [10-12]. Meanwhile, encouraging multi-location evaluations have been conducted and observed in Vietnam, where "Yunza" hybrid varieties performed much better than local inbred cultivars in yield, drought tolerance and fertilizer input [13]. Nevertheless, the 14. TPSGMS-based hybrid varieties accounted only $0.5 \%$ of total 2691 wheat varieties released in China from 2002 to 2018 [14]. In addition, few hybrid varieties were applied in main producing areas such as Yellow-Huai River wheat zone of China, where inbred varieties perform well in yield while most hybrid varieties available did not exhibit enough yield advantage. An important cause for this situation is that only eight practically usable TPSGMS lines across China were developed over past 20 years, which greatly restricted the opportunities and efficiency of creating heterotic hybrids although ten thousands of restorers were test-crossed. A practical TPSGMS line is commonly characterized as stable sterile duration for $\geq 20$ days in different years $[15,16]$, outcrossing rate for $\geq 70 \%$ [17], dwarf plant height at $50-70 \mathrm{~cm}$ [15], as well as good combining ability and agronomic traits [9]. In addition, the recessive genes controlled sterility only express at a restricted temperature and day-length condition and produces a low ratio of sterile plants in segregating population [15]. These factors result in a low efficiency in developing practical TPSGMS lines by conventional breeding methods. Therefore, the current breeding strategy needs to be improved to develop more practical wheat TPSGMS lines for producing more heterotic hybrids.

The Doubled Haploid (DH) technique allows to homogenize a heterozygous material in one generation. It has been widely used in crop breeding to improve the efficiency of selection and to accelerate the breeding process [18-22]. In wheat, DHs can be produced by intergeneric cross between wheat (Triticum aestivum L.) and maize (Zea mays L.). This methodology has become an integral part of many commercial wheat breeding programs. It has advantages of stable induction and few genotypic restrictions in producing haploids over anther and microspore cultures [23, 24]. This study aimed to evaluate the efficiency of developing wheat TPSGMS lines by using $\mathrm{DH}$ technique based on wheat $x$ maize in breeding program with sterile materials derived from different filial generations of $F_{1}, F_{2}$ and $F_{3}$.

\section{Results}

\section{Successful generation of $\mathrm{DH}$ lines by wheat $\times$ maize system}

During summer sowings in 2014-2016, wheat DHs were produced from four $F_{1} s$ and sterile plants selected from $F_{1}$ and $F_{2}$ generations by wheat $\times$ maize system (Fig. 1 ). A total of $920 \mathrm{DH}$ lines were obtained from all eight crosses (Table 1). In Dec. 2016, a major frost caused damage of plants that were heading, resulting in partial failure to obtain DH seeds. Variance analysis showed that there were significant difference in the rate of immature embryos $(P=0.00)$ and haploid seedling rate (No. of seedlings germinated from every 100 inoculated embryos, $P=0.00$ ) among different combinations, suggesting that embryo rate and haploid seedling rate were more susceptible to genotypes. The averages of embryo rate, seedling rate of embryos and chromosome doubling rate of seedlings were $36.76,62.65$ and $86.42 \%$ respectively, exhibiting a good efficiency in DH production as demonstrated in our previous studies [25-29].

Temperate climate at Kunming, especially from May to October, allows planting spring and vernalized winter wheat materials throughout the year under natural condition (Fig. 2 and Supplemental Data 1), which facilitates mass production of wheat DHs by wheat $\times$ maize crosses because fresh pollens are available from multiple rounds of planting of maize plants from late April to early November $[27,29]$.

\section{Candidates of elite DH sterile lines}

During 2016-2018, all $920 \mathrm{DH}$ lines produced from $\mathrm{F}_{1}$, $\mathrm{F}_{2}$ and $\mathrm{F}_{3}$ generations were evaluated independently using a one-year sterility test to screen candidate sterile lines (Fig. 3). A total of $295 \mathrm{DH}$ lines showed normal seed set were excluded from further analysis. These lines were mostly from $F_{1}$ generations as expected. In the 1st (Oct. 15) and 2nd (Nov. 20) sowings, 210 (33.60\%) and $66(10.65 \%)$ lines from the total of $625 \mathrm{DH}$ lines had seed setting rates less than $5 \%$, respectively. Furthermore, 41 (6.56\%) DH lines showed seed setting rate less than $5 \%$ in both sowings (Table 2, Fig. 4 and Supplemental Data 2). When further considering other desired traits of out-crossing potential, disease resistance (to stripe rust and powdery mildew), plant height (50-60 $\mathrm{cm})$, tillering and spike formation ability, 24 lines were selected from 41 lines as our final set of elite DH lines.

When sterile lines are sown on Oct. 15 (1st sowing) and Nov. 20 (2nd sowing), the critical periods for causing fertility alteration are from middle to late February and from late March to early April, respectively. Consequently, during the critical periods, the 1st sown sterile lines would go through lower temperature and shorter days to fully exhibit sterility, while the 2nd sown lines would have relatively higher temperature and longer days that can cause the early heading spikes sterile and the late heading tillers partially fertile to produce a few seeds for propagation (Fig. 2 and Supplemental Data 1).

Based on our experience, TPSGMS lines that exhibit $100 \%$ sterility in the 2 nd sowing date are usually stable in sterility but are difficult for propagation, which make them not suitable for practical application. In 


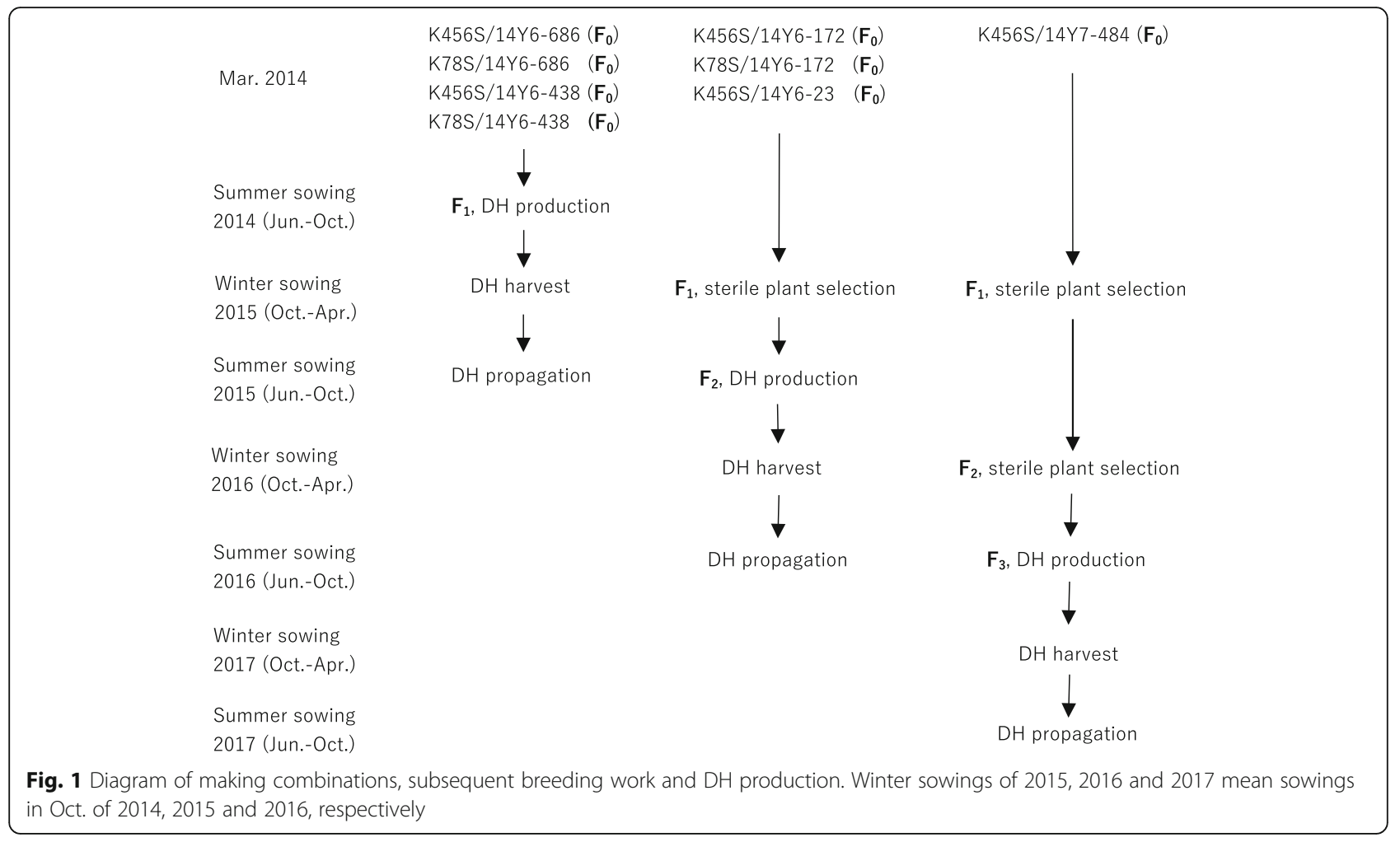

southwest of China wheat is normally sown from middle Oct. to early Nov., thus a TPSGMS line with seed setting rate $<5 \%$ in both sowing dates (from Oct. 15 to Nov. 20) would meet the demand for safe production of qualified hybrid seeds.

\section{$F_{1}$-derived elite sterile lines exhibited stable sterility}

To test the stability of sterility in different years, ten $\mathrm{F}_{1}$ derived elite DH sterile lines were evaluated in two growing seasons from 2016 to 2018 by planting in two and ten different sowing dates respectively (Fig. 3). In the 2016/2017 growing season, the seed setting rates of all lines were 0 in the 1st sowing date, and ranged from 2.98 to $4.87 \%$ in the 2 nd sowing date (Table 3). In further tests using ten sowing dates in the $2017 / 2018$ season, the seed setting rates of the ten elite lines were $<1 \%$ from the 1 st to the 3rd sowings (Oct.22-Nov. 5), <5\% till the 5th sowing (Nov. 19), and $\geq 50 \%$ in the 10 th sowing (Dec. 24), suggesting sowings before Nov. 5-19 were optimum for hybrid seed production, and sowings after Dec. 24 is suitable for propagation of these sterile lines (Fig. 5 and Supplemental Data 3).

Table 1 Parameters of producing doubled haploids with $F_{1} s$ and selected sterile plants of $F_{2}$ and $F_{3}$

\begin{tabular}{|c|c|c|c|c|c|c|c|c|c|}
\hline \multirow[t]{2}{*}{ Year } & \multirow[t]{2}{*}{ Combinations } & \multicolumn{8}{|c|}{ Statistics in producing embryos, haploid seedlings and DH lines ${ }^{*}$} \\
\hline & & NS & $\mathrm{NC}$ & $\mathrm{NE}$ & NHS & $\mathrm{NDH}$ & RE (\%) & RHS (\%) & RCD (\%) \\
\hline $2014 / 2015$ & $\mathrm{~K} 78 \mathrm{~S} / 14 \mathrm{Y}_{6}-686$ & 25 & 756 & 136 & 84 & 76 & $17.99^{a}$ & $61.76^{\mathrm{C}}$ & $90.48^{\text {cde }}$ \\
\hline 2014/2015 & $\mathrm{K} 456 \mathrm{~S} / 14 \mathrm{Y}_{6}-686$ & 15 & 510 & 214 & 146 & 110 & $41.96^{\mathrm{d}}$ & $68.22^{\mathrm{d}}$ & $75.34^{\mathrm{a}}$ \\
\hline $2014 / 2015$ & $\mathrm{~K} 78 \mathrm{~S} / 14 \mathrm{Y}_{6}-438$ & 32 & 928 & 362 & 152 & 130 & $39.01^{c}$ & $41.99^{a}$ & $85.53^{b c}$ \\
\hline $2014 / 2015$ & $\mathrm{~K} 456 \mathrm{~S} / 14 \mathrm{Y}_{6}-438$ & 24 & 654 & 334 & 180 & 148 & $51.07^{\mathrm{g}}$ & $53.89^{b}$ & $82.22^{b}$ \\
\hline 2015/2016 & $\mathrm{K} 78 \mathrm{~S} / 14 \mathrm{Y}_{6}-172$ & 16 & 564 & 152 & 110 & 102 & $26.99^{b}$ & $72.37^{\mathrm{e}}$ & $92.73^{e}$ \\
\hline 2015/2016 & $\mathrm{K} 456 \mathrm{~S} / 14 \mathrm{Y}_{6}-172$ & 18 & 532 & 234 & 147 & 128 & $43.98^{e}$ & $62.82^{c}$ & $87.07^{b c d}$ \\
\hline 2015/2016 & $\mathrm{K} 456 \mathrm{~S} / 14 \mathrm{Y}_{6}-23$ & 11 & 360 & 173 & 130 & 119 & $48.06^{f}$ & $75.14^{\mathrm{e}}$ & $91.54^{\text {de }}$ \\
\hline 2016/2017 & $\mathrm{K} 456 \mathrm{~S} / 14 \mathrm{Y}_{7}-484$ & 40 & 1292 & 323 & 210 & 107 & $25.00^{b}$ & $65.02^{\mathrm{cd}}$ & $-{ }^{* *}$ \\
\hline \multicolumn{2}{|c|}{ Total / average } & 181 & 5596 & 1928 & 1159 & 920 & 36.76 & 62.65 & 86.42 \\
\hline
\end{tabular}

${ }^{*} N S$ No. of pollinated spikes, NC No. of caryopses, NE No. of embryos obtained, NHS No. of haploid seedlings germinated from embryos, NDH No. of DHs, RE Rate of embryo (NE.NC ${ }^{-1}$ ), RHS Rate of haploid seedling (NHS.NE ${ }^{-1}$ ), RCD Rate of chromosome doubling (NDH.NHS ${ }^{-1}$ )

${ }^{* *}$ Part of colchicine treated plants was damaged by frost. Different letters in the last three rows mean significant at 0.05 level 


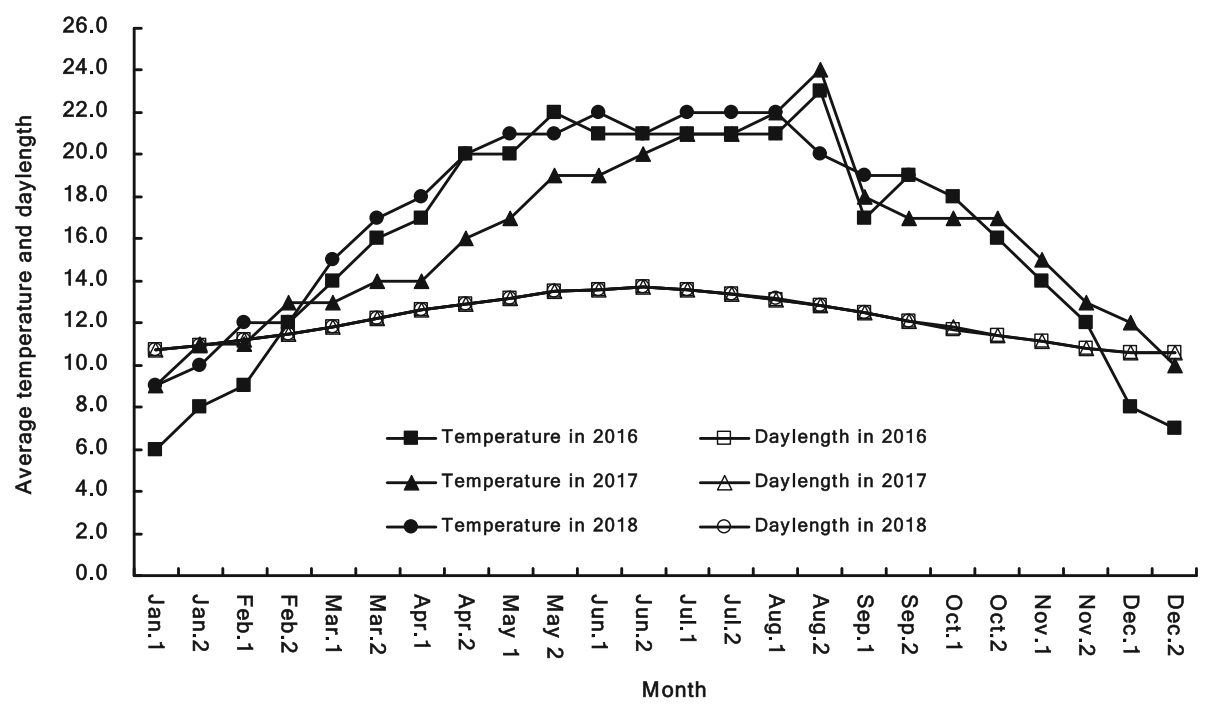

Fig. 2 Average temperature and daylength of every half month from 2016 to 2018 at Kunming. Jan.1 and Jan.2 mean the first and second half of Jan., the same as that of other months; data were collected from Jan. 1, 2016 to Sep. 30, 2018

The ten elite TPSGMS lines derived from $\mathrm{F}_{1}$ generation showed nearly $100 \%$ sterility in 3 years when sown from Oct. 15 to Nov. 5, although the average temperatures varied from $12{ }^{\circ} \mathrm{C}$ to $15^{\circ} \mathrm{C}$ during the critical periods from the second half Feb. to the first half Mar. (Fig. 2 and Supplemental Data 1). These lines are stable in sterility in 3 years' tests, thus selected for hybrid breeding. Stable sterility is a prerequisite to commercial utilization for a TPSGMS line [16].

\section{Sterility stability of $\mathrm{F}_{2}$-derived elite sterile lines was} confirmed by repeat tests

Ten $\mathrm{F}_{2}$-derived DH lines were selected in 2016/2017 and were evaluated again in the 2017/2018 growing season (Fig. 3). The seed setting rates of all lines were 0 in the 1st sowing, and ranged from 1.99 to $4.04 \%$ in the 2nd sowing (Table 4). These ten lines showed stable sterility in 2 years, were selected to plant in ten sowing dates for further evaluation in stability of sterility, as well as determination of suitable sowing times for hybrid seed production and self propagation.

\section{Elite DH sterile lines showed high out-crossing ability} In winter sowing of 2018/2019, the out-crossing potential of 20 elite TPSGMS lines derived from $F_{1}$ and $F_{2}$ generations were evaluated. The out-crossing rates of the 20 lines ranged from 70.46 to $93.90 \%$ with an average of $82.87 \%$. There were 13 lines, including 8 derived from $\mathrm{F}_{2}$ generation, showing out-crossing rate $>80 \%$, 4 lines between 75 and $80 \%$, and 3 lines between 70 and
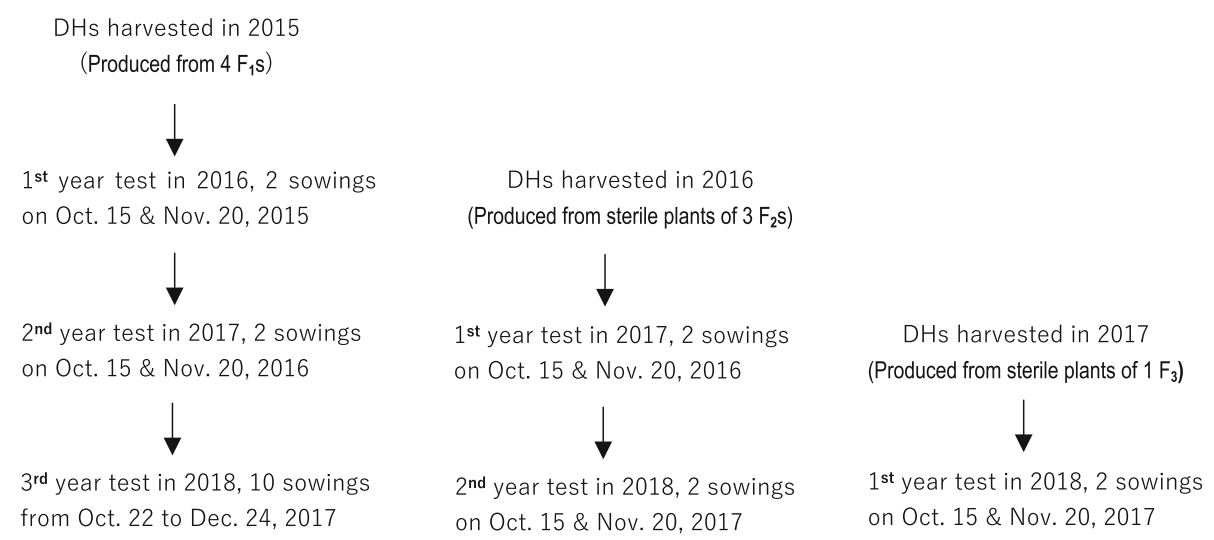

Fig. 3 Diagram of sterility tests for $\mathrm{DH}$ s produced from $\mathrm{F}_{1}, \mathrm{~F}_{2}$ and $\mathrm{F}_{3}$ generations. Each sowing in the 3rd year test was conducted at 7 days interval from Oct. 22 to Dec. 24, 2017 
Table 2 Results of sterile lines selection in sterility tests of 2015/2016, 2016/2017 and 2017/2018 seasons

\begin{tabular}{|c|c|c|c|c|c|c|c|}
\hline \multirow[t]{2}{*}{ Year } & \multirow{2}{*}{$\begin{array}{l}\text { Source of } \\
\text { DH lines }\end{array}$} & \multirow{2}{*}{$\begin{array}{l}\text { No. of } \\
\text { tested lines }\end{array}$} & \multicolumn{3}{|c|}{ No. of lines with seed setting rate $<5 \%$} & \multicolumn{2}{|c|}{ Finally selected elite lines } \\
\hline & & & 1st sowing & 2nd sowing & Both sowings $^{a}$ & Number & $\%$ \\
\hline 2015/2016 & $F_{1}$ & 314 & 71 & 23 & $13(4.14 \mathrm{C})$ & 10 & $3.18 \mathrm{C}$ \\
\hline $2016 / 2017$ & $\mathrm{~F}_{2}$ & 204 & 74 & 24 & $15(7.35 \mathrm{~B})$ & 10 & $4.90 \mathrm{~A}$ \\
\hline $2017 / 2018$ & $\mathrm{~F}_{3}$ & 107 & 65 & 19 & $13(12.15 \mathrm{~A})$ & 4 & $3.74 \mathrm{~B}$ \\
\hline Total & & 625 & 210 & 66 & $41(6.56)$ & 24 & 3.84 \\
\hline
\end{tabular}

${ }^{a}$ Figures in parentheses denote the corresponding percentages in yearly tested lines. Different letters in the sixth and eighth rows mean significant at 0.01 level by U-test
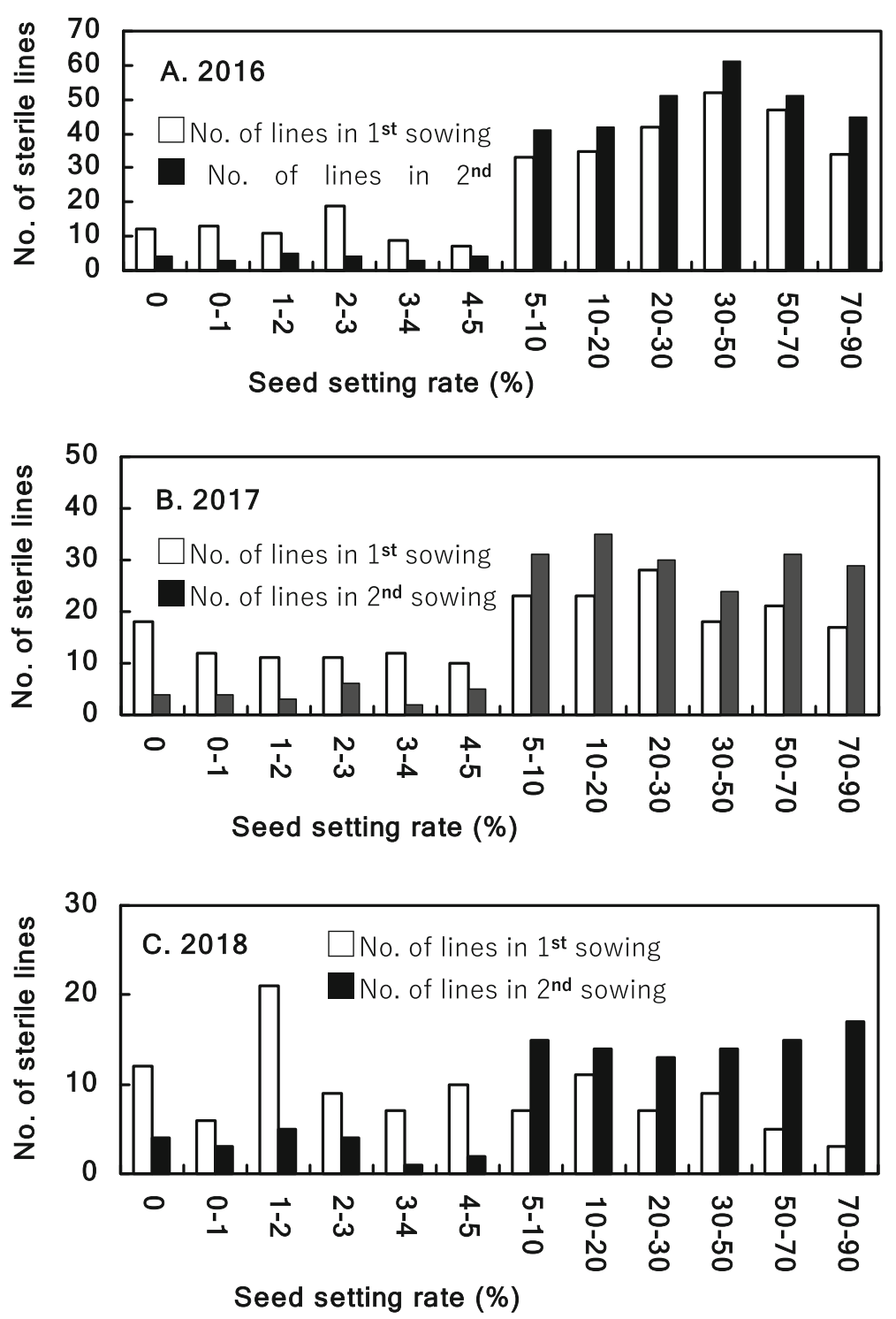

Fig. 4 Distribution of seed setting rate of 625 DHs in first year sterility tests during 2016-2018. 314 DH lines were tested in 2016 (a), 204 DH lines in 2017 (b), and 107 DH lines in 2018; the 1st sowing dates were on Oct. 15 in 2015 (a), 2016 (b) and 2017 (c), respectively; the 2nd sowing dates were on Nov. 20 in 2015 (a), 2016 (b) and 2017 (c), respectively 
Table 3 Seed setting rates of $F_{1}$ derived elite lines in second round sterility test in 2017

\begin{tabular}{|c|c|c|c|c|c|c|c|c|c|c|c|}
\hline Tested code & L1 & L2 & L3 & L4 & L5 & L6 & L7 & L8 & L9 & L10 & CK \\
\hline Line code & 16DH002 & 16DH005 & 16DH014 & 16DH087 & 16DH102 & 16DH106 & $16 \mathrm{DH} 203$ & $16 \mathrm{DH} 256$ & $16 \mathrm{DH} 284$ & $16 \mathrm{DH} 303$ & K78S \\
\hline 1st sowing ${ }^{a}$ & 0.00 & 0.00 & 0.00 & 0.00 & 0.00 & 0.00 & 0.00 & 0.00 & 0.00 & 0.00 & 0.00 \\
\hline 2nd sowing ${ }^{b}$ & 4.72 & 3.76 & 4.23 & 4.21 & 2.98 & 4.42 & 3.79 & 4.87 & 4.81 & 4.46 & 4.85 \\
\hline
\end{tabular}

${ }^{\mathrm{a}}$ Sowing on Oct. 15, 2016, ${ }^{\mathrm{b}}$ sowing on Nov. 20, 2016

75\% (Table 5). All 20 lines showed high out-crossing potential after only one round of selection after DH production. Thus, doubled haploids showed a great efficiency in fixation of this trait, which confirmed our previous results [17]. More lines derived from $F_{2}$ generation appeared to have better out-crossing ability $(>80 \%)$ compared with those from $F_{1}$ generation, suggesting that one more cycle of selection before $\mathrm{DH}$ production is helpful to further enhance the target trait. The results of out-crossing rates here were obtained by pollination with nearly unlimited pollen supply, it needs to be further confirmed in practical hybrid seed production.

\section{Comparison of DH breeding efficiency among generations}

Based on the seed setting rates $<5 \%$ in both sowing dates, $41 \mathrm{DH}$ sterile lines, including 13, 15, and 13 lines derived from $F_{1}, F_{2}$ and $F_{3}$ generations, respectively, were selected (Table 2), the breeding efficiency (percentage of selected
$\mathrm{DH}$ lines in total $\mathrm{DH}$ lines tested) was 4.14, 7.35 and $12.15 \%$ for $F_{1}, F_{2}$ and $F_{3}$, respectively. A total of 24 elite lines were selected based on further evaluation of other desired traits. The breeding efficiency for $F_{1}, F_{2}$ and $F_{3}$ was $3.18,4.90$ and $3.74 \%$, respectively. U-test analyses indicated that there were significant differences $(P<0.01)$ in breeding efficiency of producing DHs from $F_{1}, F_{2}$ and $F_{3}$ generations (Table 2). The trend of breeding efficiency for a single trait (sterility) was in the order of $F_{3}>F_{2}>F_{1}$, while for comprehensive traits was $F_{2}>F_{3}>F_{1}$, which suggests that producing DHs from $\mathrm{F}_{2}$ generation is better in overall breeding efficiency.

\section{Discussion}

Discovery and application of male sterility is the foundation of commercial production of hybrid wheat. The chance of creating elite heterotic hybrids is correlated with the number of sterile lines and restorers available

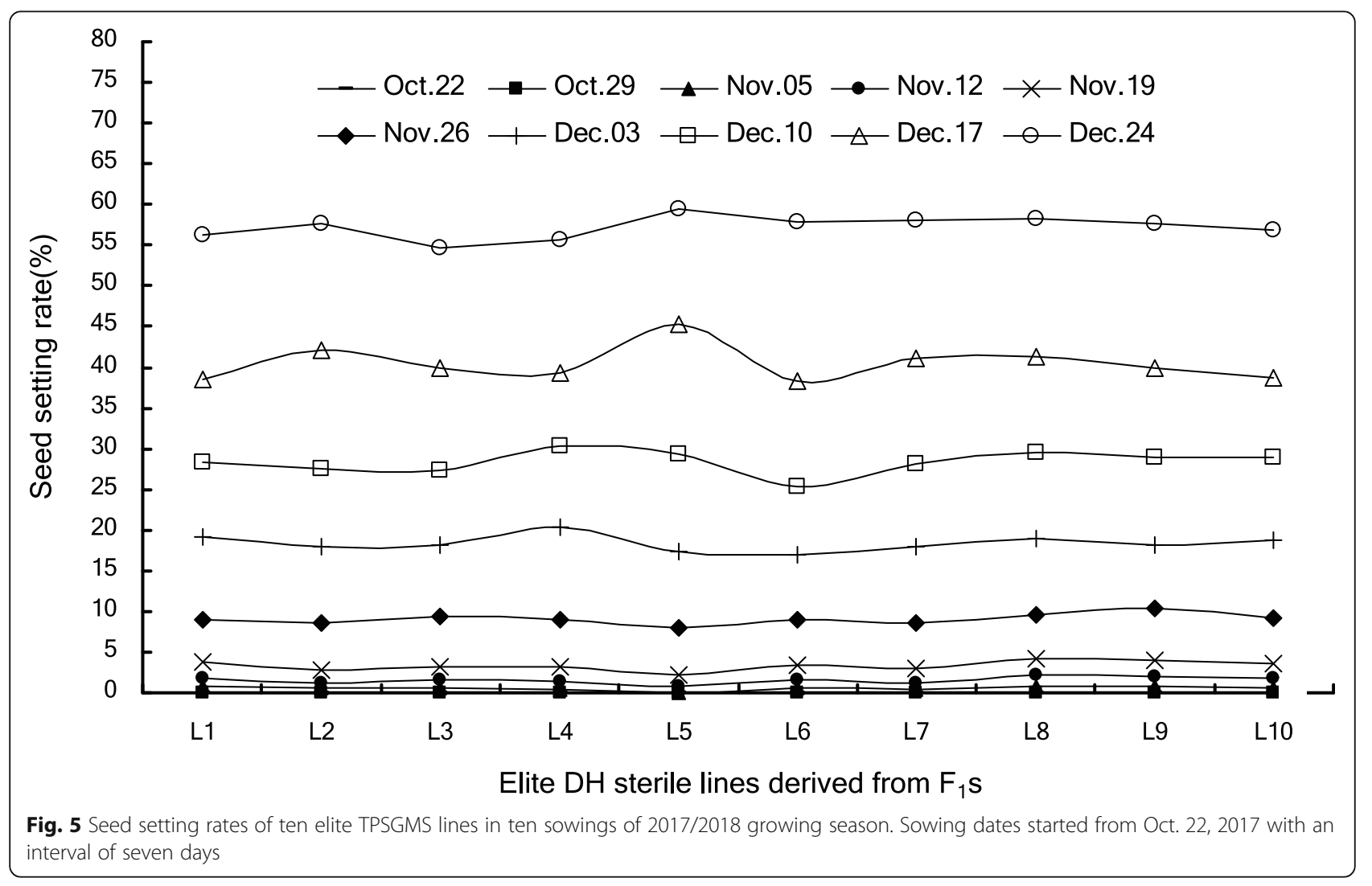


Table 4 Seed setting rates of $F_{2}$ derived elite lines in second round sterility test in 2018

\begin{tabular}{|c|c|c|c|c|c|c|c|c|c|c|c|}
\hline Tested lines & 17DH007 & 17DH013 & 17DH026 & 17DH039 & 17DH065 & 17DH104 & 17DH157 & 17DH158 & 17DH192 & 17DH202 & CK \\
\hline 1st sowing ${ }^{a}$ & 0.00 & 0.00 & 0.00 & 0.00 & 0.00 & 0.00 & 0.00 & 0.00 & 0.00 & 0.00 & 0.00 \\
\hline 2nd sowing ${ }^{b}$ & 3.76 & 2.76 & 1.99 & 3.79 & 3.72 & 4.04 & 2.38 & 3.24 & 3.17 & 3.92 & 4.09 \\
\hline
\end{tabular}

${ }^{\mathrm{a}}$ Sowing on Oct. 15, 2017, ${ }^{\mathrm{b}}$ sowing on Nov. 20, 2017; CK $=$ K78S

in breeding programs. Although the TPSGMS-based two-line hybrid wheat system was established in 1990s $[7,30]$, less than ten TPSGMS lines capable for commercial usage have been developed in north and south wheat zones of China up to now. Pedigree method is commonly used in developing TPSGMS lines [7, 15, 30, 31], however, several difficulties have hindered the breeding efficiency. The sterility of TPSGMS line is controlled by two or three recessive major genes plus several minor genes $[7,16,32-34]$, causing a very low proportion of highly sterile plants in segregating populations, especially in $\mathrm{F}_{2} \mathrm{~S}$ derived from crosses between sterile lines and normal fertile lines. When other desired traits are considered together during selection, the breeding efficiency would become extremely low. Theoretically, the probability of homozygous recessive individuals in $\mathrm{F}_{2}$ population is $1 / 4^{\mathrm{n}}$, the probability would be $1 / 2^{\mathrm{n}}$ if $\mathrm{DH}$ lines are produced from $F_{1}$, suggesting $\mathrm{DH}$ breeding is more efficient for selection of traits controlled by recessive genes, such as the sterility here. Crosses between semisterile materials and sterile lines can further increase the proportion of highly sterile plants in segregating populations of this study, which is similar in effectiveness to backcrossing with sterile lines [31].

Few effective molecular markers are currently available for marker-assisted selection in sterility of wheat TPSGMS lines [35]. Consequently, it is time-consuming to develop a genetically stable TPSGMS line because the expression of sterility needs strict temperature and light condition which is only available one season per year
[15]. In our previous breeding program, only two practical TPSGMS lines (K78S and K456S) were developed by pedigree method from 1996 to 2010, while in this study we developed 24 elite TPSGMS lines with complete homozygosity and other desired traits within 4 years by introducing $\mathrm{DH}$ techniques.

Another issue addressed in this study is to identify the ideal generation for producing DHs. Most breeders prefer to produce $\mathrm{DHs}$ from $\mathrm{F}_{1}$ generation to shorten the breeding cycles, but this approach may limit the chances for recombination [18]. Therefore, producing DHs with selected individuals from $F_{2}$ generation of single crosses or $F_{1}$ generation of pyramiding crosses seems to be better than that from $F_{1}$ generation of single crosses [36]. Similarly, Snape and Simpson (1981) inclined to produce DHs from $\mathrm{F}_{2}$ generation in barley by comparing the gain in genetic variation for six agronomic traits with $\mathrm{DH}$ lines derived from $F_{1}, F_{2}, F_{3}$ and intermated $F_{2}(S 3)$ generations [37]. In contrast, Iyamabo and Hayes (1995) did not find more favorable genotypes in $\mathrm{DH}$ lines produced from $F_{2}$ generation than that from $F_{1}$ generation in barley, therefore, they preferred to use $\mathrm{F}_{1}$ generation for producing DHs [38]. In the present study, the overall breeding efficiency of producing DHs from filial generations was in the order of $F_{2}>F_{3}>F_{1}$, indicating that $F_{2}$ generation is better for producing DHs in breeding efficiency. However, it still needs to be further investigated by comparing the breeding efficiency of producing DHs with $F_{1}$ and selected plants of $F_{2}$ and $F_{3}$ derived from the same cross.

Table 5 Out-crossing rates of 20 elite $\mathrm{DH}$ sterile lines derived from $\mathrm{F}_{1}$ and $\mathrm{F}_{2}$ in $2019^{\mathrm{a}}$

\begin{tabular}{llllllllllll}
\hline Lines & Source & ugn & bgn & SN & OR & Lines & Source & ugn & bgn & SN & OR \\
\hline 17D007 & $F_{2}$ & 59.50 & 0.00 & 40.40 & 73.64 & $16 \mathrm{D} 002$ & $F_{1}$ & 55.20 & 0.10 & 39.10 & 70.46 \\
$17 D 013$ & $F_{2}$ & 65.20 & 0.05 & 38.70 & 84.17 & $16 \mathrm{D} 005$ & $F_{1}$ & 70.30 & 0.00 & 40.20 & 87.44 \\
$17 D 026$ & $F_{2}$ & 69.70 & 0.00 & 39.60 & 88.01 & $16 \mathrm{D} 014$ & $F_{1}$ & 72.50 & 0.00 & 41.00 & 88.41 \\
$17 D 039$ & $F_{2}$ & 60.50 & 0.10 & 38.80 & 77.84 & $16 \mathrm{D} 087$ & $F_{1}$ & 65.40 & 0.00 & 43.40 & 75.35 \\
$17 D 065$ & $F_{2}$ & 70.40 & 0.00 & 38.80 & 90.72 & $16 \mathrm{D} 102$ & $F_{1}$ & 61.50 & 0.10 & 36.30 & 84.57 \\
$17 D 104$ & $F_{2}$ & 69.70 & 0.05 & 40.00 & 87.06 & $16 \mathrm{D} 106$ & $F_{1}$ & 60.20 & 0.00 & 38.60 & 77.98 \\
$17 D 157$ & $F_{2}$ & 78.50 & 0.00 & 41.80 & 93.90 & $16 \mathrm{D} 203$ & $F_{1}$ & 72.50 & 0.00 & 41.90 & 86.52 \\
$17 D 158$ & $F_{2}$ & 76.30 & 0.05 & 45.10 & 84.53 & $16 \mathrm{DH} 256$ & $F_{1}$ & 68.40 & 0.00 & 45.90 & 74.51 \\
$17 D 192$ & $F_{2}$ & 74.50 & 0.00 & 43.60 & 85.44 & $16 \mathrm{DH} 284$ & $F_{1}$ & 74.80 & 0.10 & 43.30 & 86.26 \\
17D202 & $F_{2}$ & 72.50 & 0.00 & 42.80 & 84.70 & $16 \mathrm{DH} 303$ & $F_{1}$ & 57.80 & 0.00 & 38.10 & 75.85 \\
Average & & 69.68 & 0.03 & 40.96 & 85.00 & Average & & 65.62 & 0.03 & 40.78 & 80.73 \\
\hline
\end{tabular}

${ }^{a}$ All sterile lines were sown on Oct. 15, 2018. ugn and bgn represent No. of seeds in un-bagged and bagged spikes, SN denotes No. of spikelets per spike, OR means the out-crossing rate 
Producing DHs from $\mathrm{F}_{1}$ generation had less breeding efficiency because only one round of recombination occurred and no selection was applied. As a result, a high frequency of agronomically undesirable lines were produced [37], which was confirmed in this study as most fertile lines were discarded from $F_{1}$ generation. However, as showed in this study, using $F_{1}$ generation for $\mathrm{DH}$ breeding has the edge in saving time; it could be useful for crosses with better predictability and coping with urgent needs for developing varieties with resistance to diseases, such as yellow rust for its frequently varying pathogenic races.

\section{Conclusion}

In this study we developed 20 practical TPSGMS lines of wheat. These lines showed stable sterility in replicated evaluation in multiple years, as well as good outcrossing potential and other desirable traits. We demonstrated that introducing DH technique is an efficient strategy in accelerating development of TPSGMS lines of wheat. Producing DHs from $\mathrm{F}_{2}$ generation appeared to be the better choice with balance of breeding efficiency and shortening of breeding cycle. Nevertheless, it will be necessary to conduct further investigations by using diverse genetic materials of different filial generations derived from the same combinations. More practically usable TPSGMS lines would further increase the opportunity of creating heterotic hybrids in hybrid wheat breeding.

\section{Methods}

\section{Plant materials}

Two TPSGMS lines and five semi-sterile advanced lines of wheat were used in the study (Table 6). A maize variety "Baitiannuo" was used as pollen donor in $\mathrm{DH}$ production. All wheat and maize materials were bred by Institute of Food Crops, Yunnan Academy of Agricultural Sciences, Kunming, China.

\section{Crossing and $\mathrm{DH}$ production}

Wheat materials were late sown in Jan. 2014 to make semi-sterile materials fertile for crossing with sterile lines K78S and K456S in Mar. 2014 at Kunming, Yunnan province, China $\left(25^{\circ} 02^{\prime} \mathrm{N}, 102^{\circ} 42^{\prime} \mathrm{E}\right.$, altitude 1960 $\mathrm{m})$. For DH production, maize sowing (in April) began 2 months before wheat sowing (in June) to synchronize their flowering dates. Maize was sown in three dates with an interval of 14 days.
Before producing doubled haploids, pedigree methods were adopted to select sterile plants from segregating population of $F_{1}$ and $F_{2}$ generations according to performances in sterility, out-crossing potential including glume opening and stigma exsertion [17], plant height $(50-60 \mathrm{~cm})$, resistance to yellow rust and powdery mildew, tillering ability and the yield potential. Seeds of sterile plants were harvested from regenerated tillers by cutting all spikes of sterile plants followed by intensive management in irrigation and fertilization. The crossings and subsequent breeding work and $\mathrm{DH}$ production are summarized in Fig. 1.

\section{Method of producing DHs}

For DH production, we adopted an improved protocol from previous reports $[18,23,24]$. Wheat spikes were pollinated with fresh maize pollen 24 to $48 \mathrm{~h}$ after emasculation. Pollinated tillers were cut $24 \mathrm{~h}$ after pollination and sprayed with $100 \mathrm{ppm} 2,4-\mathrm{D}$, then were cultured in growth chambers for 14 days with nutrition solution containing $100 \mathrm{mg} \mathrm{L}^{-1}$ 2,4-D, $40 \mathrm{~g} \mathrm{~L}^{-1}$ sucrose, $10 \mathrm{mg} \mathrm{L}^{-1}$ silver nitrate, $3 \mathrm{gL}^{-1}$ potassium dihydrogen phosphate and $3 \mathrm{~g} \mathrm{~L}^{-1}$ urea. The nutrient solution was replaced every 3 days. During culture, the growth chamber keeps a regime of $14 \mathrm{~h}$ darkness / $10 \mathrm{~h}$ light with light intensity of 6000 Lux, constant temperature of $25 \pm 1^{\circ} \mathrm{C}$ and relative humidity of $80 \pm 5 \%$. Embryos were aseptically dissected from 14-day caryopses and cultured on half-strength MS medium [39] under darkness at $24 \pm 1{ }^{\circ} \mathrm{C}$ until germination, then moved to the growth house at a regime of $14 \mathrm{~h}$ darkness $/ 10 \mathrm{~h}$ light (at $3000 \mathrm{Lux}$ ), keeping constant temperature of $25 \pm 1{ }^{\circ} \mathrm{C}$ and humidity of $75 \pm 5 \%$. When seedlings developed two to three tillers, the plantlets were taken out and immersed in $0.05 \%$ colchicine solution for $8 \mathrm{~h}$ at $25^{\circ} \mathrm{C}$ to induce doubling of chromosomes. Treated seedlings were transplanted into pots to grow until booting stage, then moved into greenhouse for 15 days, keeping temperature $>20^{\circ} \mathrm{C}$ to ensure fertility of $\mathrm{DH}$ plants. All plants were bagged before flowering and harvested one by one.

\section{DH sterile line selection and its stability evaluation in sterility}

The sterility of DH lines obtained during 2015-2017 was independently evaluated by sowing at two dates on Oct.15 and Nov. 20, respectively (Fig. 3). At least 10 spikes per line in each sowing were randomly bagged

Table 6 wheat materials used for developing TPSGMS lines

\begin{tabular}{ll}
\hline Materials & Description \\
\hline K78S, K456S & $\begin{array}{l}\text { Commercial TPSGMS lines, susceptible to stripe rust and powdery mildew, different in yield potential and } \\
\text { sterility, used as female parents. }\end{array}$ \\
$\begin{array}{ll}\text { 14Y6-686, 14Y6-438, 14Y6-23, 14Y6- } \\
172,14 Y 7-484\end{array}$ & $\begin{array}{l}\text { Semi-sterile advanced lines, resistant to stripe rust and powdery mildew, different in plant height, heading } \\
\text { time and yield potential, used as male parents. }\end{array}$ \\
\hline
\end{tabular}


before flowering to measure the seed setting rate. The out-crossing potential (glume opening, stigma exsertion) [17], and other important traits such as disease resistances and yield potential were also recorded. Lines with sterility higher than $95 \%$ in both sowings were kept for stability evaluation of sterility next year.

Selected lines in 2015/2016 and 2016/2017 growing seasons were repeatedly evaluated in 2016/2017 and 2017/2018 seasons. For $\mathrm{F}_{1}$-derived elite $\mathrm{DH}$ lines, we also conducted a ten-sowing assessment in the third year from Oct. 22, 2017 to Dec. 24, 2017 with an interval of 7 days. The TPSGMS line K78S was used as the check in all tests. The seed setting rate (SSR) was calculated following Yang et al. (2006) [16]:

$$
\operatorname{SSR}(\%)=g n /(s n \times 2) \times 100
$$

Where $g n$ means the number of grains from bagged spikes, $s n$ the number of spikelets. A TPSGMS line with SSR $<5 \%$ was recognized as highly sterile and qualified for hybrid seed production [16].

Temperatures during 2016-2018 were collected from a data-logger 'HUATO S100-TH' in thermometer screen near the field, and daylengths from the meteorological station of Kunming.

\section{Out-crossing potential assessment of elite sterile lines}

Twenty elite $\mathrm{DH}$ sterile lines derived from $\mathrm{F}_{1}$ and $\mathrm{F}_{2}$ generations were separately planted as 10 rows in a plot of $1 \mathrm{~m} \times 2.5 \mathrm{~m}$ surrounded by about 600 restorers on Oct. 15, 2018. Open pollination was aided by natural wind of grade 3-6, which is usual in Yunnan throughout wheat growing seasons. Twenty spikes of each line were randomly bagged before flowering. Twenty open pollinated spikes were randomly harvested from 10 rows of each line with the bagged spikes to measure the outcrossing rate (OR) of sterile lines as follow [16, 17]:

$$
\text { OR }(\%)=(u g n-b g n) /(s n \times 2) \times 100
$$

Where ugn and $b g n$ are un-bagged and bagged grain numbers at two basal florets of each spikelet respectively, $s n$ the number of spikelets per spike. $b g n$ is counted to exclude the possible self-pollination seed setting because TPSGMS lines are not always keeping $100 \%$ sterile.

\section{Evaluation of disease resistance}

Yellow rust and powdery mildew are two most important and frequently occurred diseases at Kunming. A highly susceptible cultivar was planted close to tested $\mathrm{DH}$ sterile lines as the control and spreader. The adult plant resistance of sterile lines was scored in the field according to Han et al. (2010) for yellow rust [40] and Li et al. (2015) for powdery mildew [41].

\section{Statistical analysis}

The embryo rate, haploid seedling rate and chromosome doubling rate were analyzed using one-way analysis of variance (ANOVA) followed by Fisher's least significant difference (LSD) test. U-test of multiple percentage comparison [42] was conducted for evaluating the significant differences in breeding efficiency of producing DHs from $F_{1}, F_{2}$ and $F_{3}$ generations. SPSS and Excel Office were used in statistical analyses.

\section{Supplementary information}

Supplementary information accompanies this paper at https://doi.org/10. 1186/s12870-020-02458-5.

Additional file 1: Supplemental Data 1. Raw data for Fig. 2: The temperature and daylength during 2016-2018.

Additional file 2: Supplemental Data 2. Raw data for Fig. 4: Seed setting rates in the first year's sterility test of $625 \mathrm{DH}$ lines in both sowings during 2016-2018.

Additional file 3: Supplemental Data 3. Raw data for Fig. 5: The seed setting rates of ten elite lines in ten sowings of 2017/2018 season.

\section{Abbreviations}

TPSGMS: Thermo-photo sensitive genic male sterility; DH: Doubled haploid; NS: Number of pollinated spikes; NC: Number of caryopses; NE: Number of embryos; NHS: Number of haploid seedlings germinated from embryos; $\mathrm{NDH}$ : Number of double haploids; RE: Rate of embryos; RHS: Rate of haploid seedling; RCD: Rate of chromosome doubling; SSR: Seed setting rate; gn: grain number of bagged spikes; sn: spikelet number; OR: Out-crossing rate; ugn: un-bagged grain numbers at two basal florets of each spikelet; bgn: bagged grain numbers at two basal florets of each spikelet

\section{Acknowledgments}

We are grateful to anonymous reviewers for valuable comments and suggestions on this manuscript. We thank Dr. Jacobi A and Dr. Akel S, Strube Research GmbH \& Co. KG, Germany, and Prof. Dr. Jiming Jiang, University of Wisconsin-Madison, United States for English editing of this article.

\section{Authors' contributions}

$H L$ and $S L$ conceived and designed the research; SA, AS, JG, ZY and HZ performed the experiments; $\mathrm{HL}, \mathrm{AS}$ and MY wrote the manuscript; MD and $\mathrm{KL}$ contributed to preparation of the manuscript; all authors read and approved the final manuscript.

\section{Funding}

The work was supported by the National Key Research and Development Program of China (2016YFD0101603); the Director Fund of Institute of Food Crops, Yunnan Academy of Agricultural Sciences (2013LZS003); the Talent Young Scientist Program of Ministry of Science and Technology of China; and Talent Cultivation Program of Yunnan Academy of Agricultural Sciences. The funders had no role in the design of the study and collection, analysis, interpretation of data and in writing the manuscript.

Availability of data and materials

Plant lines and data generated in this study are available upon reasonable request, from the corresponding author.

Ethics approval and consent to participate Not applicable.

Consent for publication

All authors agreed to publish.

Competing interests

The authors declare that they have no conflict of interests. 


\section{Author details}

${ }^{1}$ Institute of Food Crops, Yunnan Academy of Agricultural Sciences / Yunnan Branch of National Wheat Improvement Center, Kunming, Yunnan 650205, P. R. China. ${ }^{2}$ Filed Crops Research Institute, Agricultural Research Center, Kafr El-Shaikh 33717, Egypt. ${ }^{3}$ National Institute for Genomics and Advanced Biotechnology, National Agricultural Research Centre, Islamabad 45500, Pakistan.

Received: 18 September 2019 Accepted: 24 May 2020

Published online: 01 June 2020

\section{References}

1. Singh SP, Srivastava R, Kumar J. Male sterility systems in wheat and opportunities for hybrid wheat development. Acta Physiol Plant. 2015;37:113

2. Mühleisen J, Piepho HP, Maurer HP, Longin CFH, Reif JC. Yield stability of hybrids versus lines in wheat, barley and triticale. Theor Appl Genet. 2013; 127:309-16

3. Murai K, Ohta H, Kurushima M, Ishikawa N. Photoperiod-sensitive cytoplasmic male sterile elite lines for hybrid wheat breeding, showing high cross-pollination fertility under long-day conditions. Euphytica. 2016;212: 313-22.

4. Boeven PHG, Würschum T, Rudloff J, Ebmeyer E, Friedrich C, Longin H. Hybrid seed set in wheat is a complex trait but can be improved indirectly by selection for male floral traits. Euphytica. 2018;214:110. https://doi.org/10. 1007/s10681-018-2188-1.

5. Wilson JA, Ross WM. Male sterility interaction of the Triticum aestivum nucleus and Triticum timopheevi cytoplasm. Wheat Inform Serv. 1962;14:2930 .

6. Murai K, Tsunewaki K. Photoperiod-sensitive cytoplasmic male sterility in wheat with Aegilops crassa cytoplasm. Euphytica. 1993;67:41-8.

7. Tan CH, Yu GD, Yang PF, Zhang ZH, Pan Y, Zheng J. Preliminary study on sterility of thermo-photo-sensitive genic male sterile wheat in Chongqing. Southwest China J Agric Sci. 1992;5(4):1-6

8. Ji JH, Ru ZG, Zhang GS, Xue X, Ou XQ. Study on pollen fertility and selfed seedset of thermo-sensitive male sterile wheat line BNY. J Triticeae Crops. 2004;24:24-6.

9. Zhao CP. Status and trends of hybrid wheat research in China. J Agric Sci Technol. 2010;12(2):5-8.

10. Xiao WJ. Status and trend of hybrid wheat studies in China and abroad. Beijing Agric. 2014;3:58-60.

11. Tao J, Li SR, Zhou Q, Ren Y, Ou JM, Lei JR, et al. Research progress of thermo-photo sensitive two-line hybrid wheat in Southwest China. Chinese Agric Sci Bull. 2017;33:1-8.

12. Wang PW. Breakthrough-China has hybrid wheat varieties; 2019. http://szb. farmer.com.cn. Accessed 25 Jun 2019

13. Chen YF. Hybrid wheat varieties from Yunnan, China exhibited high yield in Vietnam; 2015. https://www.yndaily.com. Accessed 2 Jun 2015.

14. China seed industry database. Ministry of Agriculture and rural Affairs of China; 2019. http://202.127.42.145/home/index. Accessed 28 Dec 2019.

15. Gu J, Yang MJ, Tian YX, Li SX, Zhou JS, Liu K, et al. Breeding of thermophoto-sensitive genic male sterile wheat adapted to plateau climates and studies on their fertility in Yunnan. Southwest China J Agric Sci. 2002;15:5-8.

16. Yang MJ, Gu J, Liu K, Li SX, Tian YX, Yang HX, et al. Ecological adaptability of thermo-photo-sensitive genic male sterile wheat K78S in Yunnan Province. Acta Agron Sin. 2006;32:1618-24.

17. Li HS, Li SX, Zhao H, Ding ML, Cui YZ, Gu J, et al. Effects of glume opening and stigma exsertion on outcrossing seed-setting of wheat thermo-photo sensitive genic male sterile lines. J Triticeae Crops. 2015;35(12):1671-5.

18. Tadesse W, Inagaki M, Tawkaz S, Baum M, Ginkel M. Recent advances and application of doubled haploids in wheat breeding. Afr J Biotechnol. 2012; 11:15484-92.

19. Muqaddas QH, Reif JC, Li Z, Basnet BR, Dreisigacker S, Röder MS. Genomewide association mapping and genome-wide prediction of anther extrusion in CIMMYT spring wheat. Euphytica. 2017;213:73.

20. Song JY, Carver BF, Powers C, Yan LL, Klápště J, El-Kassaby YA, et al. Practical application of genomic selection in a doubled-haploid winter wheat breeding program. Mol Breed. 2017;37:117.

21. Kelliher T, Starr D, Su XJ, Tang GZ, Chen ZY, Carter J, et al. One-step genome editing of elite crop germplasm during haploid induction. Nat Biotechnol. 2019;37:287-92.
22. Wang BB, Zhu L, Zhao BB, Zhao YP, Xie YR, Zheng ZG, et al. Development of a haploid-inducer mediated genome editing (IMGE) system for accelerating maize breeding. Mol Plant. 2019;12:597-602.

23. Suenaga K, Nakajima K. Efficient production of haploid wheat (Triticum aestivum) through crosses between Japanese wheat and maize (Zea mays). Plant Cell Rep. 1989:8:263-6.

24. Niu ZX, Jiang AX, Abu Hammad W, Oladzadabbasabadi A, Xu SS, Mergoum $M$, et al. Review of doubled haploid production in durum and common wheat through wheat $\times$ maize hybridization. Plant Breed. 2014;133:313-20.

25. Gu J, Liu K, Li SX, Tian YX, Yang HX, Yang MJ. Study on the in vitro culture of cut plants in wheat haploid embryo induction by a wheat $X$ maize cross. Front Agric China. 2008;2:391-5.

26. Gu J, Yang MJ, Li SX, Tian YX, Li HS, Yang HX, et al. Study on improving frequency of chromosome doubling in wheat haploid produced by wheat × maize system. Southwest China J Agric Sci. 2012;25:19-21.

27. Gu J, Liu K, Li SX, Tian YX, Yang HX, Shan QL, et al. Preliminary study on using wheat $X$ maize to induce wheat haploid plant in natural condition of Kunming. J Triticeae Crops. 2006;26(4):23-6.

28. Liu K, Li SX, Li HS, Yang MJ, Tian YX, Zhao H, et al. Effect of simplified emasculation methods on frequency of haploid embryo produced by wheat $\times$ maize cross. Southwest China J Agric Sci. 2016;29:206-8.

29. Ding ML, Zhao H, Gu J, Li HS, Liu K, Yang MJ, et al. Research and breeding application progress of the technique of producing double haploid of wheat by wide hybridization between wheat and maize. Agric Sci Technol. 2017;18:2202-8

30. Zhao CP, Wang X, Zhang FT, Ye ZJ, Dai HJ. Status of hybrid wheat research and two-line system based on photo-thermo sensitive genic male sterility. Beijing Agric Sci. 1999;17(2):3-5.

31. Zhang JJ, Tan CH, Yu GD, Chen H, Shi YM, Li BQ. Application of backcross in developing thermo-photo sensitive genic male sterile lines of wheat. J Triticeae Crops. 1999;19(1):12-3.

32. Guo RX, Sun DF, Tan ZB, Rong DF, Li CD. Two recessive genes controlling thermo-photoperiod sensitive male sterility in wheat. Theor Appl Genet. 2006;112:1271-6.

33. Zhang LP, Zhao CP, Shan FH, Zhang FT, Ye ZJ. The mixed genetic analysis of photoperiod-temperature sensitive male sterility of BS210 in wheat. Acta Agron Sin. 2007;33(9):1553-7.

34. Dong PH, Hu YG, Guo GH, He BR, Wang LM, Yuan JG. Inheritance and chromosome location of photoperiod-thermo sensitive male sterility in wheat line Xinong 291S. Plant Breed. 2012;131:695-9.

35. Ru ZG, Zhang LP, Hu TZ, Liu HY, Yang QK, Weng ML, et al. Genetic analysis and chromosome mapping of a thermo-sensitive genic male sterile gene in wheat. Euphytica. 2015;201:321-7.

36. Chen XM, He ZH, Liu CL, Wang DS, Zhang Y, Jia JZ, et al. New wheat variety zhongmai 533 developed by wheat $\times$ maize cross. J Triticeae Crops. 2011; 31:424-9.

37. Snape JW, Simpson E. The genetical expectations of doubled haploid lines derived from different filial generations. Theor Appl Genet. 1981;60:123-8.

38. lyamabo OE, Hayes PM. Effects of selection and opportunities for recombination in doubled-haploid populations of barley (Hordeum vulgare L.). Plant Breed. 1995;114:131-6.

39. Murashige T, Skoog F. A revised medium for rapid growth and bioassays with tobacco tissue cultures. Physiol Plant. 1962;15:473-97.

40. Han DJ, Wang QL, Zhang L, Wei GR, Zeng QD, Zhao J, et al. Evaluation of resistance of current wheat cultivars to stripe rust in Northwest China, North China and the middle and lower reaches of Changjiang River epidemic area. Sci Agric Sin. 2010;43(14):2889-96.

41. Li JB, Qiao LY, Li X, Zhang XJ, Zhan HX, Guo HJ, et al. Molecular mapping of powdery mildew resistance gene $\mathrm{PmCH7124}$ in a putative wheatThinopyrum intermedium introgression line. Acta Agron Sin. 2015;41(1):4956.

42. Xu YJ, Shang HW. U-test of multiple percentages with multiple comparisons. Agric Netw Inform. 2016;2:110-4.

\section{Publisher's Note}

Springer Nature remains neutral with regard to jurisdictional claims in published maps and institutional affiliations. 